\title{
Communication process in a Lean concept
}

\author{
Daniela Gîfu ${ }^{1}$, Mirela Teodorescu ${ }^{2, *}$ \\ 1"Alexandru Ioan Cuza" University of Iaşi, Bd. Carol I no. 11, 700506, Romania \\ ${ }^{2}$ University of Craiova, 13 A. I. Cuza Street, Craiova, 200585, Romania \\ *E-mail address: mirteodorescu@yahoo.com
}

\begin{abstract}
Communication is a process we do for most of the day in our personal and professional lives; yet most of us work on it less than our other skills. We're taught about proper communication all through school and even into our college education. Every time we are stressed of the importance of clear communication. Most of us have heard the idea "listening is the most important part of communication"; but how many of us continue to work on our communication skills as an ongoing process? Systems theory is the transdisciplinary study of the abstract organization of phenomena, independent of their substance, type, or spatial or temporal scale of existence. It investigates both the principles common to all complex entities, and the (usually mathematical) models which can be used to describe them. A system can be said to consist of four things. The first is objects - the parts, elements, or variables within the system. These may be physical or abstract or both, depending on the nature of the system. Second, a system consists of attributes - the qualities or properties of the system and its objects. Third, a system had internal relationships among its objects. Fourth, systems exist in an environment. A system, then, is a set of things that affect one another within an environment and form a larger pattern that is different from any of the parts. The fundamental systems-interactive paradigm of organizational analysis features the continual stages of input, throughput (processing), and output, which demonstrate the concept of openness/closeness. A closed system does not interact with its environment. It does not take in information and therefore is likely to atrophy, that is to vanish. An open system receives information, which it uses to interact dynamically with its environment. Openness increases its likelihood to survive and prosper. Several system characteristics are: wholeness and interdependence (the whole is more than the sum of all parts), correlations, perceiving causes, chain of influence, hierarchy, suprasystems and subsystems, self-regulation and control, goal-oriented, interchange with the environment, inputs/outputs, the need for balance/homeostasis (feedback), noise analyse and evaluation, change and adaptability (morphogenesis) and equi-finality: there are various ways to achieve goals. Communication in this perspective can be seen as an integrated process - not as an isolated event (Bertalanffy von, 1968).
\end{abstract}

Keywords: communication; lean; improvement; input; output; throughput 


\section{INTRODUCTION}

Lean manufacturing means effectiveness of an enterprise to continuously change in pursuit of improvement and excellence. This is the core of the lean principle. It also means that the people within a lean manufacturing have to develop the capability to communicate effectively. Without effective communication, changes that are introduced from a continuous improvement program will be met with resistance and will lead the people towards confusion and frustration. On the cause-effect chart of communication waste drivers, there are 3 waste: deficient information quality, ineffective communication, unnecessary detail and accuracy.

True flexibility means flexibility of all resources, including human. Thus, the organizational structure of a given product development team is continuously changing. In order to provide valuable output, and to receive valuable input, a given entity within this continuously changing project relies heavily on up-to-date information about whom to communicate with, in what way, and about what. In this information producing environment, understanding both content and process type information is vital (Borowski, 2013; Dima \& Vlăduţescu, 2012). Thus, a lean manufacturing should profit from a deep insight in the intricacies, dependencies and constraints of information and communication in product development.

\section{COMMUNICATION STRUCTURE IN LEAN CONCEPT}

In product development the processed good is information flowing by means of communication, understanding these concepts thoroughly is necessary to enhance transparency. Thereby, identifying value and waste, and facilitating improvements through principles of Lean Thinking become possible (Vlăduţescu, 2013; Vlăduţescu, 2014).

Unfortunately, the term "information" is not defined universally. Across sciences the definitions differ, take different approaches and have different views. Some common examples:

a) in information sciences, "information" is seen as negative entropy, in other words the mathematical opposite of uncertainty. This definition is measurable; the lower the probability, the higher the information. It can be expressed in the equation $\mathrm{I}=-\log 2(\mathrm{P})$, wherein $\mathrm{P}$ is the probability of a case, and $\mathrm{I}$ its informational content. This definition was introduced by Shannon (Shannon C., 1948). It does not embrace context, interpretation and consciousness.

b) in physics, "information" is seen as one of the three entities that together constitute existence, alongside matter and energy (Weizsacker, 1974).

c) in social sciences, "information" is used in the context of syntax, semantics and pragmatism. In fact, there are many sciences that have different approaches. Computer linguistics seek to understand and develop mechanism of encoding and decoding of information (Herkner, 1991); in cognitive sciences, the interpretation of information is studied (Thomas, 1991); and the representation of information is of interest in media sciences (Fischer \& Wiswende, 1997).

d) in philosophy, Gregory Bateson defined information as "a difference that makes a difference" (Bateson, 1972) which is based on: information is a distinction that makes a difference (Floridi L., 2011). 
e) the management of processes, as well as certain creativity methods, embraces the interactions of humans, and thus information in thecontext of sign, language, communication and interpretation. The various approaches to information in social sciences are used for interactions of process participants (e.g., engineers).

Based upon the above elucidations, three views on information in product development can be defined:

a) information in tools, which is based on the terminology in information sciences. It embraces computer-based as well as paper-based (and other like reports from IT applications) tools;

b) information in products, which is based on the physical definition. It can be represented through function structure analysis.

c) information in processes, which is based on social sciences. It needs a context of persons and organizational circumstances. In product development processes, a very basic differentiation, is the one between content type, process type and noise type information. It is based on the purpose of the piece of information under consideration, and can be easily illustrated in a comprehensive way.

d) Content type information is intended to provide someone information about the product to be developed. Common examples are specifications, drawings, product contracts, simulations, CAD-models and the like.

e) Process type information is intended to inform someone about the context of the development, process description. Examples are schedules, job description, operation description, tools and devices used in process, expenses for product development resources, organizational charts, among many more.

f) Noise type information has no developmental purpose. Examples are different parameters of equipment (than standard), raw material different than specifications.

The waste drivers related to information quality, are: people waiting for data, information (timeliness); information waiting for people (timeliness); lack of direct access (accessibility); information hunting (accessibility); unnecessary detail and accuracy (accuracy); Critical path related queues (timeliness); Large batch size (amount, specifically: volume); over-dissemination of information (relevancy); erroneous data and information (correctness); poor knowledge re-use (accessibility); unclear goals and objectives (deficiency in contextual information quality, leading to poor relevancy); insufficient readiness to cooperate (availability, accessibility); Poor compatibility of IT resources (accessibility).

The system in lean product development is composed of objetives, resources, constraints, input, output, information flow (Smarandache \& Vlăduţescu, 2014).

Information must flow, because it is not possible for a single person to operate competitive product development processes - most products are far too complex. As it cannot be prevented, what is the best way for information to flow? Lean Product Development proposes a "seamless information flow" (McManus, 2004), in order to perform the benefits of lean processes. Thus, the questions are, what is a seam, and how can they be circumvented? In the following, it is discussed in what dimensions information can flow, and for each, examples of seams. The most obvious dimensions of information flows are spatial distances. Information is passed from a person to another, and thus information has to be transported. 
The actual distance information covers is not the same as the one between two persons; mail for example is not transported in a direct line, and a piece of electronic information may take even several itineraries at once. Distance can affect the quality and cost of information (e.g., voice becomes low with even short distances, costs for a phone call rise). To make information flows seamless in spatial dimensions, it is thus recommendable to reduce the distance of sender and receiver, or to choose information carriers which ensure constant quality and cost with increasing distance.

Another physical dimension information flows in is time. As with spatial dimensions, the time-consumption for information transfers depends on its carrier. Solid carriers like mail or clay models must be accelerated, which, generally spoken, requires more energy with increasing velocity, and a (technical) infrastructure to accomplish. This results in increasing cost with increasing speed (e.g., airmail vs. normal). Electronic carriers, on the other hand, advance at such a high speed that time-consumption is negligible. Voice is not as fast, but as it covers only short distances, the problem is negligible as well (Neacşu, 2005). Concluding, a seamless information flow in time is accomplished with carriers that do not require acceleration (Hristea \& Colhon, 2012; Colhon, 2013; Powell, 2014).

In Lean Product Development, some ideas have been proposed to enhance the visibility of information flows. R. A. Slack proposes to use a Quality Function Deployment Information Flow Framework (Slack, 1999). Therein, customer needs are translated by the means of several QFD matrices from customer needs to ultimately production requirements. Slack further assigns each step a product development phase. He states, "this framework assists in visualizing the core product development information flow" (Slack, 1999), but it represents idealized segments of the product development process rather than to reveal the underlying value stream activities.

It is the representation of a logical, somewhat theoretical information flow, and thus does not help to identify opportunities for process improvement at all. Task, senders and receivers are not identified at all. McManus proposes "war rooms" to make information visible. In these, key information is kept on the walls for all to see, as "a time-honored method for high-priority projects" (McManus, 2004). The same strategy is proposed by Oppenheim for the Lean Product Development Flow (LPDF) framework (Oppenheim, 2004). The obvious problem of information displayed in a room is, that in order to see it, one has to move there, as rooms have a limited size.

Thus, this approach can only make sense for small projects, where all participants work closely together. Otherwise, the display of information is limited to those who have access to the war room (in the case of LPDF, management), and still has to be transformed and transported to other participants. For simpler processes, McManus proposes "a progress board or a simple web page". A web page has the great advantage of virtual omnipresence, but can increase the effort to represent information. McManus thus assumes it should be maintained without major effort (McManus, 2004).

A board organised as a system, input data, output data and processed data with "andon" data that emphiseze critical processes as alarms, then influence the feedback process. The board can be placed in production line customized for production tean, maintenance team, qualiy team. Also can be organized succesfully, Info Center Corners, classified on different activities: Safety and security, Delivery, Quality, Cost, Maintenance, Human Resources, Environment, each one with its specific tasks. Of interest in the product development context is not the social interdependency, but rather the Process interdependency - problems that potentially inhibit smooth information flow or that deteriorate information quality. The lean approach to these problems is to be found in the 
activities involved in the process of information transfer, as Lean Thinking allows evaluating activities according to their contribution to customer value.

The first step of interpersonal information transfers across tasks is the encoding of knowledge into suitable information carriers. Information transferred has to be clear, concise, visible, easy to decode.

The second step is the actual sending of information carriers. Sending itself does generally not take a lot of time nor resources: It is a mouse click, an utterance, or giving a letter to internal mail (Grabara, Modrak \& Dima, 2014; Costoiu, M., Plesu, V., Isopescu, R., Soriga, S. G., Alesincu, S. H., \& Arsene, 2012). However, there are two aspects of importance. First, the timing of sending is the sender's only way to influence the point in time when the information arrives at the receiver. Ideas from Lean Manufacturing propose to send information the instant it is pulled. This way it is assured that (a) receiving and actual perception are timely close together, as the receiver is expecting the information, and (b) in the case of short duration of transfer, feedback and control are easily possible, as an "communication channel" (Thomas, 1991) is already opened. Sending information the instant it is requested does not make sense at all neither for information that is not requested (but which is to be omitted anyhow, according to the Pull principle), nor for long or unpredictable transfer durations (Dascălu, 2013).

The data are divided in daily, weekly, monthy, quarterly, yearly information.

Scorecard document incorporates all kind of data from process and involved teams in process. It is a Pull document used to emphasize the achievements of the system.

When an organization embarks on a Lean manufacturing transformation, the management often makes the mistake of under-communicating the plan to the workforce by a factor of 10 . Typically, a communication may take place once or twice in meetings or organizational documents but does not integrate the new vision into all communication materials in a consistent, across-the-board way (Siminică \& Traistaru; Traistaru \& Avram, 2014).

Once the Lean manufacturing journey is underway, management's goal should be to reinforce the new Lean plan using all types of communication (newsletters, emails, meetings, memos, boards, andons, etc). In other words, each time an employee is informed about Lean, they should have this idea reinforced in nine other ways. Do not underestimate the importance of communication in bringing about change (Stoica, 2007). Put yourself in the employee's shoes; "Why do I have to change what I am doing?" Consider creating the "Burning Platform" reason for Lean needs to be implemented, and become a Lean thinking organization. It is common for management to use a Communication Team to help create and deploy the overall Lean Communication Plan.

\section{CONCLUSIONS}

The truth is the communication process is clear and concise. It's a two-way street and we need to make sure the recipient understands the intention of the communication as well as the content. It may appear to be an extra step in the process; however, confirming the correct translation of a communication string is critical to the success of value-added communication.

Culture is a set of rules and standards shared by members of an organization, which when acted upon by the members - produce behavior that falls within a range that the organization considers proper and acceptable. Culture is a learned process and is developed by the organization as a response to the working environment established by the 
organization's leadership and management team. Culture can have a positive or negative impact on the organization's performance. We have to consider that "effectiveness is a habit" as Peter Drucke said.

Communication is one aspect of the improvement process that you can't have too much of. However, an ineffective communication has the ability to derail any improvement process. Be diligent in your communication planning. Let's prevent having "failure to communicate".

Remember "It takes a different kind of thinking to solve a problem than the kind of thinking that produced the problem" - said Albert Einstein.

\section{ACKNOWLEDGMENT}

This work was partially supported by the grant number 33C/2014, awarded in the internal grant competition of the University of Craiova.

\section{References}

[1] J. P. Womack, D. T. Jones, D. Roos (1990). The Machine That Changed the World. MIT Press.

[2] M. Holweg, Journal of Operations Management 25 (2) (2007) 420-437.

[3] D. Bailey (2008). Automotive News calls Toyota world No 1 car maker. Reuters.com. Reuters. Retrieved 19 April 2008.

[4] Andrzej Borowski, International Letters of Social and Humanistic Sciences 14 (2014) 7-17.

[5] Ş. Vlăduţescu, E. M. Ciupercă (2013). Next Flood Level of Communication: Social Networks. Aachen: Shaker Verlag.

[6] J. F. Krafcik, Sloan Management Review (1988).

[7] Andrzej Borowski, International Letters of Social and Humanistic Sciences 11 (2014) $1-168$.

[8] Luciano Floridi (2011). The Philosophy of Information. Oxford University Press.

[9] Marian Siminică, Aurelia Traistaru, International Journal of Education and Research 1(12) 2013.

[10] I. C. Dima, Ş. Vlăduţescu (2012). Persuasion elements used in logistical negotiation: Persuasive logistical negotiation. Saarbrucken: LAP Lambert Academic Publishing.

[11] A. Thomas (1991). Grundriss der Sozialpsychologie, Teil 1: Grundlegende Begriffe und Prozesse. Göttingen: Hogrefe.

[12] W. Herkner (1991). Lehrbuch Sozialpsychologie. Bern: Huber.

[13] Aurelia Traistaru, Marioara Avram, International Letters of Social and Humanistic Sciences 13 (2014) 79-88.

[14] Florentin Smarandache, Ştefan Vlăduţescu (2014). Communication Neutrosophic Routes. Columbus, OH: Educational Publishing. 
[15] T. Ohno (1988). Toyota Production System. Productivity Press.

[16] James P. Womack, Daniel T. Jones (2003). Lean Thinking. Free Press.

[17] L. von Bertalanffy, (1968). General systems theory. New York: Braziller.

[18] Ştefan Vlăduţescu (2013). What Kind of Communication Is Philosophy. Jokull.

[19] C. E. Shannon, Bell System Technical Journal 27 (1948) 379-423 and 623-656,

[20] Andrzej Borowski, International Letters of Social and Humanistic Sciences 4 (2013) 70-74.

[21] B. M. Dascălu (2014). Echivocul imagologic în Caietele lui Emil Cioran. Studii de Ştiinţă şi Cultură.

[22] Carl Friedrich Freiherr von Weizsäcker (1980). The Unity of Nature. New York and London: Farrar-Straus.

[23] Ştefan Vlăduţescu (2014). Communication on the difficult route of lie. International.

[24] L. Fischer, G. Wiswede (1997). Kommunikation und Medienwirkung. In: Grundlagen der Sozialpsychologie. München: Oldenbourg

[25] Andrzej Borowski, International Letters of Social and Humanistic Sciences 2 (2014) 110-121.

[26] Ştefan Vlăduţescu (2014). From Personal and Social Relationships to Social Networks. International.

[27] B. W. Oppenheim (2004). Lean Product Development Flow. Systems Engineering.

[28] H. L. McManus (2004). Product Development Value Stream Analysis and Mapping Manual (PDVSM) - Beta Draft. Cambridge, MA: Lean Aerospace Initiative .

[29] B. M. Dascălu (2006). Germanitatea şi literele române. Bucureşti: Editura Fundaţia Culturală Ideea Europeană.

[30] Ştefan Vlăduţescu, European Scientific Journal 9(32) (2013).

[31] R. A. Slack (1999). The Application of Lean Principles to the Military Aerospace Product Development Process. Cambridge, MA: Massachusetts Institute of Technology.

[32] Ștefan Vlăduțescu (2013). Principle of the Irrepressible Emergence of the Message. Jokull.

[33] Jason L. Powell, International Letters of Social and Humanistic Sciences 7 (2014) 22-30.

[34] Andrzej Borowski, International Letters of Social and Humanistic Sciences 7 (2013) 113-118.

[35] Janusz Grabara, Vladimir Modrak, Ioan Constantin Dima, International Letters of Social and Humanistic Sciences 15 (2014) 148-156.

[36] Ștefan Vlăduțescu, International Letters of Social and Humanistic Sciences 13 (2014) 71-78.

[37] D. S. Stoica, Revista Transilvană de Ştiinţe ale Comunicării 5 (2007) 60-64. 
[38] Andrzej Borowski, International Letters of Social and Humanistic Sciences 6 (2013) $68-74$.

[39] Jason L. Powell, International Letters of Social and Humanistic Sciences 16(1) (2014) 19-30.

[40] Tomasz Lis, Paula Bajdor (2013). Sales Logistics as a Model Used by Companies Fulfilling Individual Customer's Needs. In: Challenges in Contemporary Management. Monograph. Scientific Editors Anna Lemańska-Majdzik, Piotr Tomski, Sekcja Wydaw. WZ PCzęst, Czestochowa.

[41] Hristea F., Colhon M., Fundamenta Informaticae, 119(1) (2012) 61-86.

[42] Ștefan Vlăduțescu, International Letters of Social and Humanistic Sciences 10 (2014) 100-106.

[43] Stoica D. S. Revista Transilvană de Ştiinţe ale Comunicării 5 (2007) 60-64.

[44] Colhon, M. (2013). Automatic Lexical Alignment between Syntactically Weak Related Languages. Application for English and Romanian. In Computational Collective Intelligence. Technologies and Applications (pp. 266-275). Springer Berlin Heidelberg.

[45] Ştefan Vlăduţescu (2014). From Personal and Social Relationships to Social Networks. International.

[46] I. Iancu, N. Constantinescu, M. Colhon, International Journal of Computers Communications \& Control 4(5) (2010) 525-531.

[47] Ștefan Vlăduțescu, International Letters of Social and Humanistic Sciences 4 (2014) 73-81.

[48] Ștefan Vlăduțescu, International Letters of Social and Humanistic Sciences 15 (2014) 164-170.

[49] Ștefan Vlăduțescu, Journal of Studies in Social Sciences 7(1) (2014).

[50] J. Grabara, M. Kolcun, S. Kot, International Journal of Education and Research 2(2) (2014).

[51] P. Bajdor, I. Grabara, Journal of Studies in Social Sciences 7(2) (2014).

[52] Ştefan Vlăduţescu (2013). Three Diachronic Paradigms of Communication. International.

[53] Costoiu M., Plesu V., Isopescu R., Soriga S. G., Alesincu S. H., Arsene I. (2012). Electronic Document Management Information System for Universities. Chemical Engineering.

[54] Neacşu S. (2005). Sistemul informaţional statistic în învăţământul românesc după 1990. Ed. Fundaţiei Univ. pentru Toţi.

[55] Ștefan Vlăduțescu, Journal of Sustainable Development Studies 6(1) (2014).

[56] Ioan Constantin Dima, Janusz Grabara, Vladimir Modrak, International Letters of Social and Humanistic Sciences 15(2) (2014) 148-156.

[57] Jason L. Powell, International Letters of Social and Humanistic Sciences 15(2) (2014) 106-118. 
[58] Jason L. Powell, International Letters of Social and Humanistic Sciences 16(2) (2014) $108-121$.

[59] Jason L. Powell, International Letters of Social and Humanistic Sciences 16(2) (2014) 132-143.

[60] Jason L. Powell, International Letters of Social and Humanistic Sciences 16(2) (2014) 177-183.

[61] Jason L. Powell, International Letters of Social and Humanistic Sciences 17(1) (2014) $1-60$. 